\title{
La Tesorería como unidad estratégica en la gerencia actual
}

\author{
Atencio Finol, Aneida *
}

\section{La Tesorería constituye una} unidad estratégica que debe manejar en forma efectiva y eficiente los recursos financieros de una empresa. Ese concepto encierra el manejo de las entradas y salidas de los mismos.

A la gerencia actual se le presentan grandes retos para operar responsablemente esos recursos, por cuanto el gerente de hoy está rodeado de constantes cambios en el entorno, a veces difíciles de sortear. Problemas como la restricción o negativa para el otorgamiento de divisas para la compra de insumos, las grandes distorsiones generadas por los fuertes controles de precio, carencia de una política coherente para atacar la inflación, que se traduce en una presión alcista de los precios; demandan la implementación de estrategias que sirvan de base para prever o atenuar el impacto de esos cambios en la empresa. De allí que es tarea de la tesorería, actuar con antelación suficiente para evitar problemas mayores.

Venezuela no es la excepción, y ante la complejidad de los escenarios que se viven en la actualidad, la tesorería debe ingeniárselas para defender los intereses de la empresa. Partiendo de ello es indispensable llevar una planificación financiera ordenada, que vaya de la mano para atender los cambios que cada día son más complejos.

El tesorero debe ser proactivo, debe anticiparse a los cambios y variaciones que los mercados experimenten; debe ser un planificador por excelencia, y realizar un cuidadoso manejo de los recursos, para evitar lamentarse más adelante. Para ello la tecnología de avanzada contribuye en mucho para atender esos cambios. De esta manera planificada, le será más fácil enfrentar los retos, así como establecer un cronograma de entradas y salidas de dinero, sin que se afecte considerablemente el flujo de caja de la empresa. Aunado a ello podrá conocer sus disponibilidades diarias y sus excedentes permitiendo optimizar los mismos.

Para lograr efectivamente esa planificación y el control de los recursos, la tesorería debe contar con el apoyo de toda la organización; ya que el tesorero se convierte en gestor de esos recursos y debe velar por el cumplimiento del

* Economista, Magíster en Gerencia de Empresas, mención Gerencia Financiera. Profesora Invitada en el Programa Gerencia de Empresas, nivel maestría de la División de Estudios para Graduados de la Facultad de Ciencias Económicas y Sociales (FCES) de la Universidad del Zulia (LUZ). Vice-presidenta de la empresa BRIASCA. 
cronograma de entradas y salidas de dinero. Todo ello va de la mano en una tarea coordinada con la estructura departamental o divisiones de la compañía, por cuanto debe existir una importante conexión entre la tesorería y el resto de los departamentos de la empresa.

En este sentido, también son de importancia fundamental las políticas financieras de la empresa, partiendo de que estas deben planificarse oportunamente. Asimismo, deben mantenerse excelentes relaciones con las instituciones financieras con las cuales trabaja la empresa, ya que eso hace más fácil la comunicación con estas; que se constituyen en un apoyo importante. Al respecto Casanovas y Fernández (2003) advierten que las técnicas de gestión de tesorería se han ido sofisticando progresivamente y los productos financieros que las instituciones ponen al servicio de las empresas han ido proliferando. La relación con el resto de los departamentos también es innegable; la tesorería viene a constituir la base de la supervivencia de todos ellos, por cuanto no contarían con recursos para acometer sus objetivos. La forma en que todos esos procesos se lleven, puede afectar, positiva o negativamente la supervivencia de la empresa.

Espiñeira, Sheldon y Asociados (1993) afirman que las funciones de tesorería están vinculadas al manejo de efectivo, de fondos, de moneda extranjera, de exposición y de riesgo.

Con relación al manejo del efectivo, hoy los negocios son más complejos y el medio económico cambia con mucha frecuencia, además de las innovaciones en el sector bancario, el costo del dinero cada vez es más elevado, y ello conlleva a que los gastos operativos, también mantengan una tendencia alcista. No obstante esos aspectos, cuando se cuenta con una unidad de tesorería organizada, es posible la optimización de los recursos partiendo de que se debe administrar el efectivo para así evidenciar los excedentes de este, buscando siempre la posibilidad de su inversión en los distintos instrumentos ofrecidos por el mercado, o reinvertirlos en la empresa, sin obviar la variable riesgo; y registrar cuáles son las necesidades de efectivo y cómo va a obtenerlo.

De esa manera lo que se busca es contar con el efectivo necesario, conociendo el nivel de liquidez que debe mantener en cuenta, y al hacerlo está optimizando sus recursos. Esto es posible con una tesorería centralizada que permitirá minimizar el excedente ocioso. Para Casanovas y Fernández (2003) la centralización de la tesorería es una técnica que permite mejorar el control de la posición diaria en fecha valor, y al mismo tiempo disminuir las necesidades de financiamiento gracias a un mejor aprovechamiento de recursos.

EI efectivo además, ha de asociarse al manejo de la producción e inventarios que son representativos para la generación de este. Una vez facturada la producción, esta se convierte en cuentas por cobrar, uno de los rubros de mayor performance para la empresa, que al hacerse efectivas van a alimentar la tesorería. De allí la importancia de cómo se moviliza ese efectivo.

En este escenario, el papel del servicio bancario adquiere mayor relevancia. Esto por cuanto la mayor parte de los fondos de tesorería transita por las instituciones financieras que constituyen la base sobre la cual se mueven las transacciones, y la gerencia de hoy permite contar con sistemas de información que apoyan esas transacciones. 
Muchas veces se me ha preguntado cuál es la cantidad de instituciones bancarias con la cuales debe trabajar una empresa, es decir si debo mantener cuentas con un mayor o menor número de bancos. Al respecto, siempre afirmo, por experiencia, que esto depende del tamaño de la empresa, y el ciclo operativo de la misma; sin embargo también deben tomarse en cuenta las exigencias que hacen las instituciones financieras para calificar dentro de sus carteras. Las variables cualitativas y cuantitativas juegan un papel fundamental para el análisis que realiza la institución bancaria. Entre estas variables cabe mencionar: la reciprocidad, entendiéndose por ello los movimientos diarios que la tesorería le da a las cuentas de la empresa ante la institución financiera; así como la exigencia de garantías, las cuales en ocasiones pueden limitar el crédito, la capacidad de respuesta de la empresa para afrontar esas obligaciones, el tamaño del mercado, el comportamiento de sus indicadores financieros, entre otros.

Mantener relaciones bancarias con varias instituciones, es recomendable; nunca una sola, pero si las necesarias. No debe incurrirse en múltiples cuentas si no puedes dar reciprocidad a la institución financiera, de allí la importancia de manejarse con mayor o menor número de bancos.

Ahora bien, en el manejo de fondos es importante la planificación en la obtención de financiamiento a corto y largo plazo, así como la fuente, si es interna o externa. Cuando se trata de fuentes internas, la empresa puede acudir, entre otras, a la reinversión de utilidades 0 aportes adicionales de capital. Este último es una de las mejores opciones ya que sería aporte de los accionistas y menos comprometedor para la tesorería.

Cuando se trata de fuentes externas, la empresa puede financiarse con los bancos, proveedores, pero también mediante mecanismos especiales a través de las mismas instituciones financieras como el factoring, arrendamiento, emisión de bonos, acciones, papeles comerciales, entre otros. La tesorería juega un papel importante, pues coordina estas operaciones ante la institución por constituirse en operaciones especiales que requieren igualmente de un análisis muy particular y minucioso.

También es vital para la empresa identificar sus necesidades de moneda extranjera o divisas. Muchas organizaciones en su ciclo productivo y comercialización de productos, no generan la divisa extranjera. De allí que es significativo el control sobre las transacciones en moneda extranjera, para la salud de la empresa. Más aún cuando en la actualidad en Venezuela se mantiene un control de cambio que ha generado grandes dificultades para la consecución de divisas para realizar pagos al exterior. Así, el manejo de divisas debe hacer que los pasivos en moneda extranjera se correspondan con sus activos. La posición descubierta de una divisa le genera problemas a la empresa a la hora de atender sus compromisos con el exterior. La falta de previsiones ante una devaluación afecta considerablemente los resultados económicos de la misma.

Por otro lado, la exposición como tal está referida al riesgo de variaciones en tipo de cambio y tasas de interés. Con relación a la exposición cambiaria, Hill (2001) la define como el riesgo de que las variaciones futuras en la tasa de cambio de un país afecten a la empresa. La 
tesorería de una empresa debe identificar qué montos están expuestos, y establecer niveles aceptables de exposición, es decir el nivel de tolerancia para conocer el efecto que las variaciones en tipo de cambio o tasas de interés pueden afectar la salud financiera de la empresa.

Una empresa no tiene asegurado su éxito, si en su desempeño, no contempla el riesgo como una variable fundamental. Aquí también la tesorería juega un papel prioritario no solo en el control del riesgo en moneda nacional seleccionando los mejores instrumentos de inversión sino en sus cuentas en moneda extranjera. En este caso cuando se tiene un activo o un pasivo en una moneda distinta de la moneda en que la empresa registra su contabilidad, se está en presencia de un riesgo en moneda extranjera y para ello deben identificarse las situaciones que involucran ese riesgo, y visualizar que mecanismos de cobertura puede aplicar la empresa para minimizar el mismo, y es aquí donde aparecen los mercados de dinero, futuros, forwards, swaps entre otros instrumentos de cobertura de riesgo en tipo de cambio.

En Venezuela no se dispone en la actualidad de muchas opciones, solo con el mercado de dinero para poder anticiparnos a esos cambios. También existe la posibilidad de colocar colaterales en el exterior en moneda extranjera pero eso hace más comprometedor el flujo de recursos de la empresa, de allí que en la actualidad se deba planificar muy seriamente y con mucho tino el manejo de la tesorería. Más aún si es el caso que la empresa en cuestión, no genera la divisa extranjera, y puede correr riesgos que comprometan a la empresa y a todos sus accionistas.

En síntesis, es importante destacar que en escenarios como los que hoy vivimos, la gerencia actual debe cuidar todos los aspectos asociados a la gestión del efectivo, al manejo de fondos, de moneda extranjera, exposición y riesgo, para hacer de esta una gestión exitosa, de allí la importancia de la tesorería como unidad estratégica en contexto actual.

\section{Referencias bibliográficas}
Casanovas, Montserrat y Fernández, Alfonso (2003), Nuevas tecnologías aplicadas a la Gestión de la Tesorería. Editorial Gestión 2000. Barcelona.

Espiñeira, Sheldon y Asociados (1983) Guía de Gerencia Estratégica de Tesorería. Guía realizada por la División de Consultoría Gerencial.

Hill, Charles (2001), Negocios Internacionales. Editorial McGraw Hill. 